\title{
Bloodstream infections in patients undergoing extracorporeal membrane oxygenation
}

\author{
Jian-rong Wang ${ }^{1}$, Jin-yu Huang², Wei Hư \\ Xue-ying $\mathrm{Cai}^{4}$, Wei-hang $\mathrm{Hu}^{5}$, Ying $\mathrm{Zhu}^{6}$
}

\begin{abstract}
Objective: We aimed to evaluate the incidence, risk factors, and prognosis of bloodstream infections (BSIs) during extracorporeal membrane oxygenation (ECMO) treatment in a Chinese population.

Methods: Patients receiving ECMO treatment from January 2013 to August 2019 were retrospectively studied. The incidence of BSIs was calculated. The clinical characteristics between patients with a BSI (BSI group) and without a BSI (non-BSI group)

Results: Among 69 included patients, 19 (27.5\%) developed at least one BSI. Gram-negative bacteria (73.7\%) were mainly responsible for the BSIs, with Klebsiella pneumoniae $(6 / 19,31.5 \%)$ ranking as the top related pathogen. The BSI group had a greater proportion of methicillin-resistant Staphylococcus aureus (MRSA) prophylactic regimens $(52.6 \%$ vs. $26.0 \%, P=0.036)$, a higher pre-ECMO Sequential Organ Failure Assessment (SOFA) score (11 vs. 8, $\mathrm{P}=0.008)$, more applications of continuous renal replacement therapy (CRRT) during ECMO $(63.1 \%$ vs. $36.1 \%, \mathrm{P}=0.042)$. Longer ECMO support duration, period of ventilator use before ECMO weaning and hospital stay were observed in the BSI group. The SOFA score (OR: 1.174; $95 \%$ $\mathrm{Cl}: 1.039-1.326 ; \mathrm{P}=0.010$ ) was an independent risk factor for BSIs.

Conclusion: BSIs during ECMO therapy frequently involve Gram-negative bacteria. Stringent care and monitoring should be provided for patients with high SOFA scores.
\end{abstract}

KEYWORDS: Bloodstream infection, Extracorporeal membrane oxygenation, Pathogen, Risk factors, Prognosis.

doi: https://doi.org/10.12669/pjms.36.6.2882

How to cite this:

Wang JR, Huang JY, Hu W, Cai XY, Hu WH, Zhu Y. Bloodstream infections in patients undergoing extracorporeal membrane oxygenation. Pak J Med Sci. 2020;36(6):1171-1176. doi: https://doi.org/10.12669/pjms.36.6.2882

This is an Open Access article distributed under the terms of the Creative Commons Attribution License (http://creativecommons.org/licenses/by/3.0), which permits unrestricted use, distribution, and reproduction in any medium, provided the original work is properly cited.

\section{INTRODUCTION}

Extracorporeal membrane oxygenation (ECMO) is one of the most important strategies to treat severe acute respiratory failure or cardiac failure. The application of ECMO in adults has increased

Correspondence:

Jin-yu Huang, MD.

Department of Cardiology,

The Affiliated Hangzhou Hospital of Nanjing Medical University, Zhejiang, China.

E-mail: hjyuo@163.com, skywalkerhz@hotmail.com

* Received for Publication:

May 29, 2020

* $1^{\text {st }}$ Revision Received:

* $2^{\text {nd }}$ Revision Received:

June 9,2020

* Final Revision Accepted: *

July 20,2020

Pak J Med Sci September - October 2020

rapidly since the influenza A H1N1 epidemic and the completion of the CESAR trial. ${ }^{1}$

Despite the growing implementation of adult ECMO, mortality due to severe acute respiratory failure or cardiac failure remains relatively high. The overall survival rate for these patients in the extracorporeal life support organization (ELSO) registry was $56 \%$, and it varied depending on the patient population and health care providers. ${ }^{2}$ Nosocomial infection is a complication commonly seen and usually contribute to a high mortality rate. Multiple factors increase the risk of nosocomial infection in patients receiving ECMO. ${ }^{3}$ Furthermore, the incidence of bloodstream infections (BSIs) remains substantial, thus impacting the prognosis of patients treated with ECMO. ${ }^{4,5}$ Therefore, the management of patients with a BSI during ECMO remains a challenge. 


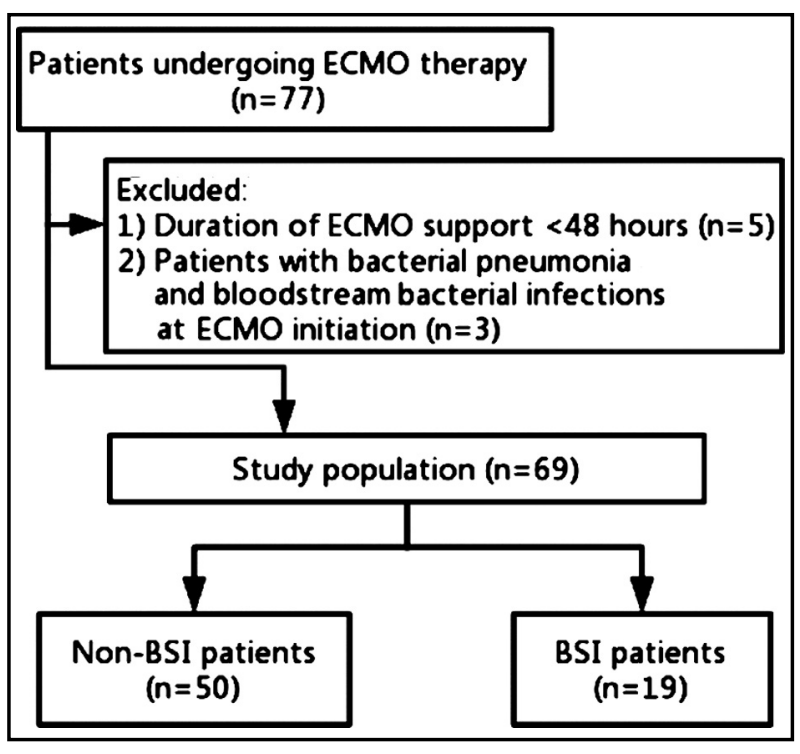

Fig.1: The study flowchart.

A thorough understanding of the clinical features of BSIs may improve the prognosis of patients receiving ECMO. ${ }^{6}$ Therefore, in this study, we aimed to explore the incidence, risk factors, and prognosis of Chinese patients undergoing ECMO with BSIs.

\section{METHODS}

All adult patients $(n=77)$ requiring ECMO at the Department of Critical Care Medicine, Affiliated Hangzhou Hospital of Nanjing Medical University, from January 2013 to August 2019 were retrospectively reviewed. Finally, a total of 69 patients receiving veno-venous or venoarterial ECMO owing to cardiopulmonary failure were included in this study (Fig.1). Demographic, clinical, and prognostic parameters were collected.

This study was approved by the local Hospital Ethics Committee (No. 2019-007-01). The informed consent was waived due to the retrospective nature of this study.

Definitions and criteria: The survival-to-discharge rate was defined as the primary outcome. ECMOrelated nosocomial pneumonia was defined as pneumonia occurring in patients receiving ECMO for more than 48 hours or withdrawn within 48 hours. ${ }^{7}$ We classified the prophylactic antibiotic regimens into two categories (Table-I).

Statistical analysis: Categorical variables were expressed as frequencies and percentages, and continuous variables were expressed as the median (range) or mean \pm standard deviation, as appropriate. Categorical variables were compared between groups using the $\chi^{2}$ or Fisher's exact test, and continuous variables were compared using the Mann-Whitney $U$ test. Multivariate logistic regression analyses were conducted to determine the independent predictive factors of nosocomial pneumonia. The variables with $\mathrm{P}<$ 0.1 in the univariate analysis were included in the multivariate analysis with a forward stepwise model. All statistical analyses were performed using SPSS 21.0 (IBM Corp., Armonk, NY, USA). All tests were two-tailed, and a value of $\mathrm{P}<0.05$ was considered statistically significant.

\section{RESULTS}

The baseline characteristic was displayed in Table-II. Myocarditis was the most common reason for ECMO treatment. A total of $30(42.5 \%)$ patients with ECMO support developed 43 episodes of nosocomial infection, with an incidence of 76.0 infections per 1000 days of ECMO. Specifically, BSIs were observed in 19 patients $(27.5 \%)$ with an incidence of 33.6 infections per 1000 days of ECMO. In addition, 14 (20.3\%) patients experienced nosocomial pneumonia, and $10(14.5 \%)$ patients had a urinary tract infection.

Gram-negative bacteria $(73.7 \%)$ were mainly responsible for the BSIs, with Klebsiella pneumoniae $(6 / 19,31.5 \%)$ ranking as the top related pathogen (Table-III). The BSI group had greater proportions of MRSA prophylactic regimens [10 (52.6\%) vs. 13 $(26.0 \%) ; \mathrm{P}=0.036]$ and CRRT [12 (63.1\%) vs. 18

Table I: Regimens of prophylactic treatment with antibiotics.

\begin{tabular}{ccc}
\multicolumn{3}{c}{$\begin{array}{c}\text { Table I: Regimens of prophylactic } \\
\text { treatment with antibiotics. }\end{array}$} \\
\hline Group & Prophylactic Antibiotics & $\begin{array}{c}\text { No. of } \\
\text { patients } \\
(n=69)\end{array}$ \\
\hline Group 1 Piperacillin/tazobactam+teicoplanin & 6 \\
Piperacillin/tazobactam+linezolid & 6 \\
Piperacillin/tazobactam+daptomycin & 6 \\
Piperacillin/tazobactam+vancomycin & 4 \\
Imipenem/cilastatin+teicoplanin & 1 \\
Group 2 Piperacillin/tazobactam & 32 \\
Cefoperazone/sulbactam & 2 \\
Meropenem & 2 \\
Imipenem/cilastatin & 2 \\
Piperacillin/tazobactam+moxifloxacin & 2 \\
Cefoperazone/sulbactam+moxifloxacin & 1 \\
Cefmetazole & 1 \\
Cefuroxime & 1 \\
Amoxicillin/clavulanic acid & 1 \\
Moxifloxacin & 1 \\
Cefatriaxone & 1 \\
\hline
\end{tabular}

Vol. $36 \quad$ No. $6 \quad$ www.pjms.org.pk 1172 
Table-II: Baseline characteristics.

\begin{tabular}{lc}
\hline Characteristic & $\begin{array}{c}\text { Study population } \\
(n=69)\end{array}$ \\
\hline Demographic data & \\
Age, years & $42(18-77)$ \\
Gender, female & $26(37.7)$ \\
Primary disease & \\
Myocarditis & $40(58.0 \%)$ \\
Coronary heart disease & $13(18.8 \%)$ \\
Pneumonia & $(8.7 \%) / 1.4 \%) / 1(1.4 \%)$ \\
$\quad$ (viral/interstitial/aspergillus) & \\
Pulmonary contusion & $3(4.3 \%)$ \\
Pulmonary arterial hypertension & $2(2.9 \%)$ \\
Lung cancer with airway obstruction & $1(1.4 \%)$ \\
Aortic dissection & $1(1.4 \%)$ \\
Allergic shock & $1(1.4 \%)$ \\
MRSA prophylactic regimens & $23(33.3 \%)$ \\
Laboratory findings (Pre-ECMO) & \\
White blood cell, 10 $/$ mm ${ }^{3}$ & $11.5(2.2-37.7)$ \\
Hemoglobin, g/dL & $120.0(61-176)$ \\
Platelets, $10^{3} /$ mm ${ }^{3}$ & $174(11-857)$ \\
CRP, mg/dL & $32(1-194)$ \\
Lactate, mM & $3.8(1.0-20.0)$ \\
Total bilirubin, mg/dL & $14.6(4.3-131)$ \\
Creatinine, mg/dL & $98.5(44-466)$ \\
Pre-ECMO SOFA score & $8(0-22)$ \\
Pre-ECMO ventilator support, days & $0(0-9)$ \\
Pre-ECMO ICU stay, days & $0(0-4)$ \\
Pre-ECMO hospital stay, days & $0(0-14)$ \\
Veno-arterial mode & $58(84.1 \%)$ \\
Ventilator duration before & $7(0-32)$ \\
$\quad$ ECMO weaning, days & \\
ECMO support duration, h & $154(55-727)$ \\
\hline & \\
\hline & \\
\hline &
\end{tabular}

$(36.0 \%) ; \mathrm{P}=0.042]$ than the non-BSI group. The ECMO support duration [(8.0 (range: 3.6-26.0) vs. 5.8 (range: 2.3-30.3) days; $\mathrm{P}=0.001]$ and ventilator duration before ECMO weaning [10 (range: 3-26) vs. 6 (range: $0-32$ ) days; $P=0.001$ ] in the BSI group were longer than those in the non-BSI group. Similarly, a longer length of hospitalization was observed in the BSI group than in the non-BSI group [25 (range: 10-39) vs.17.5 (range: 2-42) days; $\mathrm{P}=0.029$ ] (Table-IV).

The pre-ECMO SOFA score (OR: 1.174; 95\% CI: 1.039-1.326; $\mathrm{P}=0.010)$, was the independent risk factors for BSIs. Patients with a higher pre-ECMO SOFA score were more likely to experience a BSI (Table-V \& VI).

\section{DISCUSSION}

The current retrospective study found that $27.5 \%$ of the patients experienced a BSI with Gram-
Table-III: Pathogens of BSIs during ECMO support.

\begin{tabular}{lc}
\hline Microorganism species & BSI $(n=19)$ \\
\hline Gram-negative pathogens & 6 \\
Klebsiella pneumonia & 2 \\
Enterobacter aerogenes & 1 \\
A. baumannii & 1 \\
Burkholderia cepacia & 1 \\
Pseudomonas aeruginosa & 1 \\
Enterobacter cloacae & 1 \\
Serratia marcescens & 1 \\
Stenotrophomonas maltophilia & \\
Gram-positive pathogens & 2 \\
Staphylococcus epidermidis & 1 \\
Enterococcus faecium & \\
Fungi & 1 \\
Candida albicans & 1 \\
Candida parapsilosi & \\
\hline
\end{tabular}

negative bacteria as the predominant pathogen. Patients with a higher SOFA score were more likely to have a BSI. Prophylactic antibiotics with anti-MRSA activity may increase BSIs. Although BSIs were associated with a longer hospital stay, there was no significant correlation between BSI and mortality.

The BSIs prevalence in patients undergoing ECMO is reported to vary from $3 \%$ to $18 \%$, based on the region, race, and disease status; the corresponding incidence ranges from 2.98 to 20.55 episodes per 1000 days of ECMO in adults. ${ }^{8,9}$ In the current study, 19 patients (27.5\%) developed a BSI, with an incidence of 33.6 infections per 1000 days of $\mathrm{ECMO}$, which seems to be higher than the incidence reported in previous studies. We speculate that an emergent catherization in an overcrowded and contaminated ER may be responsible for this higher BSIs rate.

In this study, BSIs were mostly caused by Gram-negative bacteria. We found that Gramnegative bacteria were responsible for $73.7 \%$ of the BSIs identified, with the leading pathogens being K. pneumonia, Enterobacteraerogenes, and Staphylococcusepidermidis. Our results were partly consistent with recent studies from other single centers, which demonstrated that Enterobacteriaceae and Acinetobacter baumannii were the most common pathogens. ${ }^{3,9,10}$ In contrast, early data (1998-2008) from theELSORegistry show that themain pathogens of nosocomial infection include the Gram-positive bacteria coagulase-negative Staphylococci (15.9\%), Staphylococcus aureus (9.4\%), Candida (12.7\%), and Pseudomonas aeruginosa (10.5\%). ${ }^{1}$ However, the specific discrimination criteria of infection from contamination in the ELSO registry as well as the 
Jin-yu Huang et al.

Table-IV: Differences of characteristics between patients with and without BSIs during ECMO.

\begin{tabular}{|c|c|c|c|}
\hline Characteristics & Without BSI $(n=50)$ & With BSI $(n=19)$ & P value \\
\hline \multicolumn{4}{|l|}{ Demographic characteristics } \\
\hline Age, years & $40(18-77)$ & $44(21-67)$ & 0.872 \\
\hline Female & $19(38.0)$ & $7(36.8)$ & 0.929 \\
\hline Smoking history & $12(24.0)$ & $6(31.6)$ & 0.522 \\
\hline \multicolumn{4}{|l|}{ Primary disease } \\
\hline Myocarditis & $24(48.0)$ & $8(42.1)$ & 0.661 \\
\hline Respiratory failure & $8(16.0)$ & $4(21.1)$ & 0.725 \\
\hline Coronary artery disease & $13(26.0)$ & $6(31.6)$ & 0.643 \\
\hline \multicolumn{4}{|l|}{ Laboratory findings (Pre-ECMO) } \\
\hline White blood cell, $10^{3} / \mathrm{mm}^{3}$ & $10.65(2.20-36.7)$ & $13.3(5.2-37.7)$ & 0.256 \\
\hline Hemoglobin, g/L & $119.5(61-176)$ & $122(70-174)$ & 0.984 \\
\hline Platelets, $10^{3} / \mathrm{mm}^{3}$ & $175.0(33.0-396.0)$ & $140(11-857)$ & 0.100 \\
\hline Lactate, $\mathrm{mM}$ & $3.8(1.0-20.0)$ & $2.3(1-19)$ & 0.859 \\
\hline Total bilirubin, $\mu \mathrm{M}$ & $14.0(4.3-131.0)$ & $20.1(7.9-127)$ & 0.079 \\
\hline Creatinine, $\mu \mathrm{M}$ & $94.0(44-466)$ & $124(55-297)$ & 0.070 \\
\hline $\mathrm{CRP}, \mathrm{mg} / \mathrm{dL}$ & $22.5(1-176)$ & $59(1-194)$ & 0.192 \\
\hline \multicolumn{4}{|l|}{ Pre-ECMO data } \\
\hline Pre-ECMO CPR & $16(32.0)$ & $9(47.5)$ & 0.235 \\
\hline Veno-venous ECMO mode & $8(16.0)$ & $4(21.1)$ & 0.725 \\
\hline Pre-ECMO SOFA score & $8(0-21)$ & $11(1-22)$ & 0.008 \\
\hline Pre-ECMO ICU stay $\geq 1$ day & $12(24.0)$ & $6(31.6)$ & 0.522 \\
\hline Pre-ECMO ventilator duration $\geq 1$ day & $12(24.0)$ & $8(42.1)$ & 0.139 \\
\hline Pre-ECMO hospital stay $\geq 1$ day & $22(44.0)$ & $8(42.1)$ & 0.887 \\
\hline Pre-ECMO GCS & $15(3.0-15.0)$ & $15(3-15)$ & 0.816 \\
\hline MRSA prophylactic regimen & $13(26.0)$ & $10(52.6)$ & 0.036 \\
\hline \multicolumn{4}{|l|}{ During ECMO data } \\
\hline IABP during ECMO & $13(26.0)$ & $8(42.1)$ & 0.194 \\
\hline CRRT during ECMO & $18(36.0)$ & $12(63.1)$ & 0.042 \\
\hline Corticosteroid (methylprednisolone) before and during ECMO, mg & $545(0-3100)$ & $560(0-2860)$ & 0.793 \\
\hline ECMO support duration, days & $5.8(2.3-30.3)$ & $8.0(3.6-26.0)$ & 0.001 \\
\hline \multicolumn{4}{|l|}{ Before ECMO weaning data } \\
\hline ventilator duration before ECMO weaning, days & $6(0-32)$ & $10(3-26)$ & 0.001 \\
\hline \multicolumn{4}{|l|}{ Prognosis } \\
\hline ECMO weaning (Success) & $40(80.0)$ & $8(42.1)$ & 0.147 \\
\hline hospital stay, days & $17.5(2-42)$ & $25(10-39)$ & 0.029 \\
\hline Survival-to-discharge rate & $33(66.0)$ & 8 (42.1) & 0.532 \\
\hline
\end{tabular}

site of infectious episodes were not reported, which may diminish the reliability of pathogens reported in the past decades. ${ }^{7}$ The shift towards more Gramnegative infections is thought to be related to the changing resistance patterns, biofilm formation, and exposure to multi-drug resistant bacteria in healthcare environments. ${ }^{11}$

Controversies still exist concerning the necessity of prophylaxis for ECMO treatment. In our research, all patients were given intravenous prophylactic antibiotics during the process of ECMO support. However, the incidence of overall infection was still high. Additionally, BSIs were more commonly seen in patients with anti-MRSA regimens. This increased likelihood of BSI in the anti-MRSA group is probably linked to dysbiosis (imbalance of guts microbial environment) of the intestinal flora and bacterial translocation. Therefore, we speculate that prescription of anti-MRSA medications to prevent BSIs should be used with caution in ECMO patients. Other studies also have shown that antibiotic prophylaxis did not reduce ECMOrelated infection. ${ }^{5}$ Thus, the ELSO Infectious Disease Task Force does not recommend the administration of antimicrobial agents to prevent infectious complications during ECMO support 
Table-V: Univariate analysis of risk factors for BSIs.

\begin{tabular}{|c|c|c|}
\hline Risk factors & OR $(95 \% C I)$ & P value \\
\hline \multicolumn{3}{|l|}{ Demographic characteristics } \\
\hline Age, years & $1.000(0.970-1.032)$ & 0.980 \\
\hline Female gender & $1.051(0.352-3.135)$ & 0.929 \\
\hline Smoker & $1.462(0.456-4.685)$ & 0.523 \\
\hline \multicolumn{3}{|l|}{ Primary disease } \\
\hline Myocarditis & $0.788(0.271-2.289)$ & 0.661 \\
\hline Respiratory failure & $1.400(0.368-5.332)$ & 0.622 \\
\hline Coronary artery disease & $1.314(0.414-4.171)$ & 0.644 \\
\hline \multicolumn{3}{|c|}{ Laboratory findings (Pre-ECMO) } \\
\hline White blood cell $\left(10^{3} / \mathrm{mm}^{3}\right)$ & $1.033(0.963-1.108)$ & 0.366 \\
\hline Hemoglobin, g/L & $0.998(0.978-1.019)$ & 0.880 \\
\hline Platelets $\left(10^{3} / \mathrm{mm}^{3}\right)$ & $0.999(0.994-1.004)$ & 0.708 \\
\hline Lactate, $\mathrm{mM}$ & $1.038(0.931-1.158)$ & 0.501 \\
\hline Total bilirubin, $\mu \mathrm{M}$ & $1.017(0.994-1.041)$ & 0.152 \\
\hline Creatinine, $\mu \mathrm{M}$ & $1.006(0.998-1.014)$ & 0.117 \\
\hline CRP mg/dL & $1.007(0.998-1.016)$ & 0.122 \\
\hline \multicolumn{3}{|l|}{ Pre-ECMO data } \\
\hline Pre-ECMO CPR & $1.912(0.650-5.626)$ & 0.239 \\
\hline Veno-venous ECMO mode & $1.400(0.368-5.332)$ & 0.622 \\
\hline Pre-ECMO SOFA score & $1.174(1.039-1.326)$ & 0.010 \\
\hline Pre-ECMO ICU stay $\geq 1$ day & $1.462(0.456-4.685)$ & 0.523 \\
\hline $\begin{array}{l}\text { Pre-ECMO ventilator } \\
\text { duration } \geq 1 \text { day }\end{array}$ & $2.303(0.753-7.047)$ & 0.144 \\
\hline $\begin{array}{l}\text { Pre-ECMO hospital } \\
\text { stay } \geq 1 \text { day }\end{array}$ & $0.926(0.318-2.694)$ & 0.887 \\
\hline Pre-ECMO GCS & $0.982(0.886-1.088)$ & 0.727 \\
\hline MRSA prophylactic regimen & $3.162(1.053-9.502)$ & 0.040 \\
\hline \multicolumn{3}{|c|}{ During -ECMO data } \\
\hline IABP during ECMO & $2.070(0.683-6.271)$ & 0.198 \\
\hline CRRT during ECMO & $3.048(1.018-9.124)$ & 0.046 \\
\hline $\begin{array}{l}\text { Corticosteroid before } \\
\text { and during ECMO, mg }\end{array}$ & $1.000(0.999-1.001)$ & 0.877 \\
\hline $\begin{array}{l}\text { ECMO support } \\
\text { duration, days }\end{array}$ & $1.103(1.003-1.212)$ & 0.043 \\
\hline \multicolumn{3}{|l|}{ Before ECMO weaning data } \\
\hline $\begin{array}{l}\text { Ventilator duration before } \\
\text { ECMO weaning, days }\end{array}$ & 1.109 (1.021-1.206) & 0.014 \\
\hline \multicolumn{3}{|l|}{ Prognosis } \\
\hline ECMO weaning (Success) & $0.429(0.134-1.369)$ & 0.153 \\
\hline hospital stay, days & 1.065 (1.005-1.129) & 0.034 \\
\hline Survival-to-discharge rate & $0.708(0.240-2.091)$ & 0.532 \\
\hline
\end{tabular}

and advises not to prolong it beyond 48 hours after cannulation. ${ }^{12}$

There is a higher risk of nosocomial infection with a longer ECMO duration. Several previous studies have reported a similar clear association between the risk of nosocomial infection and ECMO duration. ${ }^{8,13,14}$ Burket et al. have reported that the incidence of BSIs increased from 9.5 to 64.5 infections per 1000 days of ECMO for
Table-VI: Multivariate analysis of risk factors for BSIs.

\begin{tabular}{lcc}
\hline Risk factors & OR $(95 \%$ CI $)$ & P value \\
\hline Pre-ECMO SOFA score & $1.174(1.039-1.326)$ & 0.010 \\
MRSA prophylactic regimen & 0.104 \\
CRRT during ECMO & 0.365 \\
ECMO support duration, days & 0.146 \\
Ventilator duration before & 0.041 \\
$\quad$ ECMO weaning, days & \\
\hline
\end{tabular}

patients with ECMO lasting from 3-10 days to 21-30 days. ${ }^{5}$ Moreover, the duration of ventilator support before ECMO weaning was similarly related to BSI occurrence as long-term ventilator support increased the incidence of ventilatorassociated pneumonia and secondary BSIs. ${ }^{4}$ Of note, BSIs may also prolong the duration of ECMO or the duration of ventilator use. In the currents study, patients with BSI had a significantly longer duration on ECMO (8 vs. 5.8 days) and ventilator duration before ECMO weaning (10 vs. 6 days) although we failed to prove that the duration of ECMO or ventilator duration was an independent risk factor for BSIs due to the limited sample size.

The pre-ECMO SOFA score, which reflects multiple organ function, was an independent risk factor for BSIs in the current study. This result confirmed the previous findings that a higher SOFA score before cannulation is an independent risk factor for overall infectious complications and for BSIs. ${ }^{14-16}$ Previous studies have also found an association between renal failure and BSIs in patients with veno-venous ECMO as well as a relationship between hepatic failure and BSIs in patients with veno-arterial ECMO. ${ }^{17}$ There are several explanations for these results. First, invasive procedures, medication, electrolyte disorders, and blood infusion may increase the risk of bacterial contamination. Second, organ failure may also lead to prolonged ECMO and ventilator support, which increase the possibility of infection. Therefore, ECMO support should be initiated as early as possible to restrain the development of multiple organ dysfunction.

The impact of BSIs on clinical outcomes is still largely unknown. Some studies have demonstrated a significantly elevated mortality in pediatric patients with BSIs compared with those without BSIs, ${ }^{18}$ but other studies of patients receiving venovenous ECMO have shown that BSIs have no effect on mortality..$^{19}$ In this study, the differences between the two groups were not significant, whereas the survival-to-discharge rates were $66 \%$ for the nonBSI group and $44.5 \%$ for the BSI group. Advances in 
sepsis care and earlier initiation of antibiotics may reduce the impact of BSIs on the patient prognosis.

Limitations of the study: This study has several limitations that must be acknowledged. First, it was a retrospective, single center study, and the sample size was small. Second, the source of BSI was difficult to identify, and the ratio of primary BSI to secondary BSI was not reported. Third, our analysis only included the first episode of BSI and thus may underestimate the overall incidence of BSIs.

\section{CONCLUSION}

Gram-negative bacteria are the predominant pathogens causing BSI during ECMO treatment. Severe organ failure increases the risk of BSI in patients receiving ECMO.

\section{REFERENCES}

1. ECLS Registry Report. Available at: https://wwwelsoorg/ Registry/Statisticsaspx Accessed 22th October 2019.

2. Barbaro RP, Odetola FO, Kidwell KM, Paden ML, Bartlett $\mathrm{RH}$, Davis MM, et al. Association of hospital-level volume of extracorporeal membrane oxygenation cases and mortality. Analysis of the extracorporeal life support organization registry. Am J Respir Crit Care Med. 2015;191(8):894-901. doi: 10.1164/ rccm.201409-1634OC

3. O'Neill JM, Schutze GE, Heulitt MJ, Simpson PM, Taylor BJ. Nosocomial infections during extracorporeal membrane oxygenation. Intensive Care Med. 2001;27(8):1247-1253. doi: 10.1007/s001340101029

4. Sun HY, Ko WJ, Tsai PR, Sun CC, Chang YY, Lee CW, et al. Infections occurring during extracorporeal membrane oxygenation use in adult patients. J Thorac Cardiovasc Surg 2010;140(5):1125-1132 e1122. doi: 10.1016/j.jtcvs.2010.07.017

5. Burket JS, Bartlett RH, Vander Hyde K, Chenoweth CE. Nosocomial infections in adult patients undergoing extracorporeal membrane oxygenation. Clin Infect Dis. 1999;28(4):828-833. doi: $10.1086 / 515200$

6. Hsu MS, Chiu KM, Huang YT, Kao KL, Chu SH, Liao CH. Risk factors for nosocomial infection during extracorporeal membrane oxygenation. J Hosp Infect. 2009;73(3):210-216 doi: 10.1016/j.jhin.2009.07.016

7. Garner JS, Jarvis WR, Emori TG, Horan TC, Hughes JM. CDC definitions for nosocomial infections, 1988. Am J Infect Control. 1988;16(3):128-140. doi: 10.1016/0196-6553(88)90053-3

8. Schmidt M, Brechot N, Hariri S, Guiguet M, Luyt CE, Makri $\mathrm{R}$, et al. Nosocomial infections in adult cardiogenic shock patients supported by venoarterial extracorporeal membrane oxygenation. Clin Infect Dis. 2012;55(12):1633-1641. doi: $10.1093 / \mathrm{cid} /$ cis783

9. Aubron C, Cheng AC, Pilcher D, Leong T, Magrin G, Cooper DJ, et al. Infections acquired by adults who receive extracorporeal membrane oxygenation: Risk factors and outcome. Infect Control Hosp Epidemiol. 2013;34(1):24-30. doi: 10.1086/668439

10. Vincent JL, Bihari DJ, Suter PM, Bruining HA, White J, NicolasChanoin $\mathrm{MH}$, et al. The prevalence of nosocomial infection in intensive care units in Europe. Results of the European Prevalence of Infection in Intensive Care (EPIC) Study. EPIC International Advisory Committee. JAMA. 1995;274(8):639-644.

11. Maillet JM, Guerot E, Novara A, Le Guen J, Lahjibi-Paulet $\mathrm{H}, \mathrm{Kac} \mathrm{G}$, et al. Comparison of intensive-care-unit-acquired infections and their outcomes among patients over and under 80 years of age. J Hosp Infect. 2014;87(3):152-158. doi: 10.1016/j jhin.2014.03.011
12. O'Horo JC, Cawcutt KA, De Moraes AG, Sampathkumar P, Schears GJ. The Evidence Base for Prophylactic Antibiotics in Patients Receiving Extracorporeal Membrane Oxygenation. ASAIO J. 2016;62(1):6-10. doi: 10.1097/MAT.00000000000000287

13. Bizzarro MJ, Conrad SA, Kaufman DA, Rycus P. Infections acquired during extracorporeal membrane oxygenation in neonates, children, and adults. Pediatr Crit Care Med. 2011;12(3):277-281. doi: 10.1097/PCC.0b013e3181e28894

14. Pieri M, Agracheva N, Fumagalli L, Greco T, De Bonis M, Calabrese MC, et al. Infections occurring in adult patients receiving mechanical circulatory support: the two-year experience of an Italian National Referral Tertiary Care Center. Med Intensiva. 2013;37(7):468-475. doi: 10.1016/j. medin.2012.08.009

15. Austin DE, Kerr SJ, Al-Soufi S, Connellan M, Spratt P, Goeman E, et al. Nosocomial infections acquired by patients treated with extracorporeal membrane oxygenation. Crit Care Resusc. 2017;19(Suppl 1):68-75.

16. Butler DF, Lee B, Molitor-Kirsch E, Newland JG. Extracorporeal Membrane Oxygenation-Associated Bloodstream Infections In Children. Pediatr Infect Dis J. 2017;36(3):346-347. doi: 10.1097/ INF.0000000000001431

17. Menaker J, Galvagno S, Rabinowitz R, Penchev V, Hollis A, Kon Z, et al. Epidemiology of blood stream infection in adult extracorporeal membrane oxygenation patients: A cohort study. Heart Lung. 2019;48(3):236-239. doi: 10.1016/j.hrtlng.2019.01.004

18. Kim GS, Lee KS, Park CK, Kang SK, Kim DW, Oh SG, et al Nosocomial Infection in Adult Patients Undergoing VenoArterial Extracorporeal Membrane Oxygenation. J Korean Med Sci. 2017;32(4):593-598. doi: 10.3346/jkms.2017.32.4.593

19. Marcos M, Soriano A, Inurrieta A, Martinez JA, Romero A, Cobos $\mathrm{N}$, et al. Changing epidemiology of central venous catheter-related bloodstream infections: increasing prevalence of Gram-negative pathogens. J Antimicrob Chemother. 2011;66(9):2119-2125. doi: 10.1093/jac/dkr231

\section{Authors' Contributions:}

Jian-rong Wang data analysis and wrote the manuscript.

Jin-yu Huang contributed to interpretation of the data.

Wei $\mathrm{Hu}$ designed most of the investigation.

Xue-ying Cai, Wei-hang $\mathrm{Hu}$, and Ying Zhu contributed to data collection and literature search. All authors are accountable for the accuracy or integrity of the work.

Authors:

1. Jian-rong Wang, MS Department of Critical Care Medicine,

2. Jin-yu Huang, MD. Department of Cardiology,

3. Wei Hu, MS Department of Critical Care Medicine,

4. Xue-ying Cai, MS. Department of Critical Care Medicine,

5. Wei-hang $\mathrm{Hu}, \mathrm{MS}$. Department of Critical Care Medicine, Zhejiang Hospital, Zhejiang, China.

6. Ying Zhu, MS Department of Critical Care Medicine,

1-4,6: The Affiliated Hangzhou Hospital of Nanjing Medical University, Zhejiang, China. 